\title{
Thyroid Gland Anaplastic Carcinoma by AJCC v7 Stage
}

National Cancer Institute

\section{Source}

National Cancer Institute. Thyroid Gland Anaplastic Carcinoma by A/CC v7 Stage. NCI Thesaurus. Code C140999.

A term that refers to the staging of thyroid gland anaplastic carcinoma, following the rules of the TNM AJCC V7 classification system. 